of its trustworthy character that scarcely any statement contained in it has had to be withdrawn in the preparation of the new edition. The subject-matter has been widened by the inclusion of further particulars concerning alloy steels of the class frequently employed in automobile construction, and by the addition of sections on specifications, in regard to which the author expresses decided opinions, based on a wide experience. The treatise is of more general interest to the metallurgist than might be assumed from its title, since the description of the materials and processes of casehardening and of the defects that may occur in casehardened objects, involves the discussion of many other points of importance in the treatment and use of steel. On all these subjects, the advice given is sound and admirably clear in its expression. Only two minor points have been noted for criticism. There is no mention of nichrome carburising boxes, although these are now frequently used, and justify by their long life the increased cost. Plating with copper, as a means of local protection against carburisation, is still spoken of as unsatisfactory, although it has been practised with great success in the construction of aero-engine parts.

(3) The third work on our list is an elementary handbook on iron-founding. It contains a simple description of foundry methods, and the illustrations include a series of photographs of the mould for a gas-engine cylinder at various stages. Moulding is considered much more fully than melting, and the book is well adapted to give a general idea of the processes used in preparing moulds, and of the organisation of a foundry. The theoretical side is weak, and some very erroneous statements as to fuel and thermochemistry would have been better omitted. The printing and illustrations are good.

C. H. Desch.

\section{The Snakes of Ceylon.}

Ophidia Toprobanica, or The Snakes of Ceylon. By Col. Frank Wall. Pp. xxii $+58 \mathrm{I}+\mathrm{x}$ map. (Colombo: Colombo Museum, I92I.)

AOOD deal has been written on the subject of tiles of British India" (I864), and Boulenger's "Fauna of British India-Reptiles and Batrachians" (1890), both include descriptions, and in the case of the former work, remarks on the habits of many of the snakes inhabiting Ceylon. There is also the "Snakes of Ceylon" by Abercromby, a small popular treatise which appeared in I9I0. Except for the last-named work, which is very incomplete, there is, however, no book which deals solely with the snakes of Ceylon, apart from those inhabiting India, and Col. Wall, an enthusiastic naturalist and specialist on Indian snakes, in producing the volume under review has succeeded in filling a long-felt want.

The author in his work gives an account of the marine snakes which may be met with around the shores, as well as the terrestrial forms. A full description is given of every snake, and the determination of the genera and species is often facilitated by useful, if somewhat unscientific, keys. Except when dealing with the sea-snakes, Col. Wall has in most cases adopted the nomenclature used in Boulenger's Catalogue of the British Museum. Sometimes the generic and specific namcs have been altered. It is impossible without going thoroughly into the various contested points to say whether the author is in every case justified in departing from Boulenger's classification, although he occasionally appears to have good reasons for so doing. We are not, however, always inspired with confidence in Col. Wall's judgment. Thus "until I am satisfied of their specific unity I prefer to regard them as distinct species" is the dogmatic reason he gives when advocating specific distinction for certain forms of Kraits, held by Boulenger, in spite of their distinctive coloration, to be only geographical varieties of the same species.

A feature of the book is the very full account given of the habits of the snakes. The author has had practical experience of the reptiles in their native haunts, and his descriptions of their feeding and breeding habits add greatly to the value of the work. There are also some interesting remarks on the subject of distribution. Many snakes inhabiting upland regions have a very restricted habitat, neither ascending nor descending beyond certain limits. The elevated ranges and peaks, where tl:e lower slopes merge into the low country, are just as effectually isolated as if they were surrounded by the sea.

Much space is devoted to the subject of snake-bite, for the benefit of the medical practitioner, and a number of illustrative cases from the records of various doctors are given.

E. G. B.

\section{Japanese Social and Economic Life.}

The Foundations of Japan: Notes made during Journeys of 6000 Miles in the Rural Districts as a Basis for a Sounder Knowledge of the Japanese People. By J. W. Robertson Scott. Pp. xxv $+446+$ plates. (London: J. Murray, I922.) 24s. net.

7 HIS is an eminently readable book, giving not only the familiar glimpses into superficial Japanese life, but also treating of the economic life of

NO. 2764 , vOL. I 10$]$ 